\title{
Modulations in Functional Traits Improve Phragmites australis Adaptation under Different Soil Water Contents in Marshes of Arid Middle-Lower Reaches of Shule River Basin, China
}

\author{
Jian Zhang, Huanjie Xie, Xiaohong Ma, Xiaogang Dong and Jianjun Cao* \\ College of Geography and Environmental Science, Northwest Normal University, Lanzhou 730070, China \\ "For correspondence: caojj@nwnu.edu.cn \\ Received 12 August 2020; Accepted 28 August 2020; Published 10 December 2020
}

\begin{abstract}
Variations in plant functional traits might reveal the adaptation strategies of vegetation under changing environment. However, few studies have focused on the variation of dominant plant functional traits in changing soil water content in marsh wetland of the arid regions. In this study, functional traits were investigated in the dominant species Phragmites australis growing at distinct soil water contents in marshes of the arid middle-lower reaches of the Shule River Basin in Northwest China. Three soil water gradients $(33.38 \pm 1.40,15.97 \pm 1.99$ and $10.22 \pm 1.61 \%)$ were identified from three marsh sites. Results showed that leaf thickness, specific leaf area, maximum height and leaf phosphorous content in $P$. australis were significantly varied from the high soil water to low soil water in arid marshes. Soil water content driven variations in functional traits of $P$. australis, mainly by its effect on soil salinity and available nitrogen, affected the functional traits of $P$. australis. In conclusion, in marshes of arid regions, P. australis adapted well to resource-poor habitats through the coordinated combination of multiple functional traits i.e., low specific leaf area, leaf nitrogen content and leaf phosphorous content, high leaf dry matter content and leaf thickness, which reflected that $P$. australis had conservative strategy. () 2021 Friends Science Publishers
\end{abstract}

Keywords: Arid regions; Functional traits; Marsh; Phragmites australis; Soil properties; Soil water content

\section{Introduction}

Plant functional traits usually explain the growth and photosynthetic rate of plants in changing environment. Plant morphological, physiological and phenological characters are used as ecological strategies and regulate the response of plants to environmental factors, influencing other nutritional levels and ecosystem function (Pérez et al. 2013; Zuo et al. 2018). Functional traits are core indicators to explore how ecosystems respond to and adapt to a vary environment (Niu et al. 2018). For instance, specific leaf area (SLA) was positively correlated with growth rate, photosynthetic capacities and nutrient concentrations (Long et al. 2011; Scalon et al. 2017), while leaf nitrogen concentration (LNC) and leaf phosphorus concentration (LPC) were positively related to each other, similar to photosynthetic rate (Chen $e t$ al. 2013; Jiang et al. 2015). It has been shown that shifts in plant functional traits and trait syndromes cope with many key ecological problems, from individuals to ecosystems (Pérez et al. 2013). Therefore, identifying plant functional traits through their responses to environmental changes is necessary to improve our ability to predict future ecosystem functions (Wright et al. 2017).

Soil water availability is one of the important factors that restrict photosynthetic assimilation of $\mathrm{CO}_{2}$ and growth of plants in arid regions (Xu and $\mathrm{Li} 2006$ ), and its content can affect soil nutrient availability and plant nutrient absorption capacity, thereby it will directly or indirectly affect the floral composition and trait characteristics (Barbieri et al. 2019). Meanwhile, the spatial pattern of soil water availability plays a vital role in the formation of plant adaptability and the determination of species composition in arid habitats (Xu and $\mathrm{Li}$ 2006). Plant adapted to different levels of soil water availability commonly develop trait variations (e.g., leaf area, leaf thickness and SLA) or a combination of traits (Kołodziejek and Michlewska 2015) which often reflects the balance of resources allocation under contrasting soil moisture conditions (Jiang et al. 2015).

Phragmites australis ( $P$. australis), as a perennial helophyte with a wide range of strong rhizomes system, is one of the most widely distributed and most productive plants all over the world and is often the single dominant species in its habitats (Liu et al. 2018). Due to its high intraspecific diversity and phenotypic plasticity, it also has widespread ecological ranges and the ability to adapt to adverse environmental conditions (Eller et al. 2017). $P$. australis distributes widely in marshes of the arid middle-lower reaches of Shule River Basin, China (Gong et al. 2011; Guo et al. 2015). This affords an opportunity to explore the variation patterns of functional

To cite this paper: Zhang J, H Xie, X Ma, X Dong, J Cao (2021). Modulations in functional traits improve Phragmites australis Adaptation under different soil water contents in marshes of arid middle-lower reaches of shule river basin, China. Intl J Agric Biol 25:52-60 
traits of $P$. australis in response to different soil water levels in the arid marshes, because it is a biological index as its morphology often changes with the change of growth environment (Engloner 2004).

The Shule River Basin is divided into the Shule River system in the north and the Suganhu Lake system in the south. The basin emerged from the end of Pliocene due to the increase in the terrain of the intermountain plains resulted from the uplift of Qilian Mountains in the north margin of the Qinghai-Tibetan Plateau. The alternation of tertiary and quaternary glacial and interglacial periods in the basin resulted in strong denudation of Qilian Mountain. Many erosive materials were transported to the middle and lower reaches, leading to the formation of some piedmont alluvial and pluvial fans (Guo et al. 2015). The impermeable basement rocks in this area are composed of conglomerate, argillaceous sandstone, and argillaceous siltstone formed in tertiary, which are cemented by calcareous mud (Ma et al. 2013; Su et al. 2020). The main aquifers overlying the basement consist of tertiary and quaternary sediments, including diluvial and alluvial sediments carried into the area by river systems, as well as aeolian and lacustrine sediments in some low-lying areas (Ma et al. 2013; Guo et al. 2015). These sediments together constitute vital unconfined and confined groundwater systems, and the general flow direction of groundwater is usually from southeast to northwest (Ma et al. 2013; Su et al. 2020). The strata of the Shule River valley are mainly quaternary gravel, sand, and loam, and groundwater is predominantly occurs in the inter-granular pore spaces of gravel and sand (Wang et al. 2014). In some places, the groundwater occurs in the form of springs, forming low-lying puddles (Ma et al. 2013). Due to shallow groundwater levels and strong evaporation, soil salinization is a severe issue in the study area (Wang et al. 2014).

Despite several prior studies have demonstrated that functional traits in $P$. australis changed with the growing environment (Engloner 2004; Eller et al. 2017); however few studies have focused on the variation of $P$. australis functional traits in different soil water content (SWC) and the relationship between $P$. australis functional traits and soil properties in marsh wetland of the arid regions. Here, this study aimed to compare the functional traits of $P$. australis that came from marshes in the Shule River Basin in China. It is hypothesized that $P$. australis functional traits (e.g., SLA, LNC, LT and LDMC) related to soil resource utilization will change significantly with SWC change and coordinated responses of several independent functional traits in $P$. australis will occur with SWC change.

\section{Materials and Methods}

\section{Study area}

This study was carried out in the middle-lower reaches of the Shule River Basin located in the west of the Hexi
Corridor, Gansu province, northwestern China (38 $54^{\prime}$ $40^{\circ} 34^{\prime} \mathrm{N}, 93^{\circ} 45^{\prime}-97^{\circ} 40^{\prime} \mathrm{E}$, altitude $1000-2800 \mathrm{~m}$ above sea level) and has continental arid climate. Annual precipitation is approximately $58-75 \mathrm{~mm}$, mostly concentrated in summer, mean annual temperature is around $6.6^{\circ} \mathrm{C}$, mean annual evaporation is $3100-3500 \mathrm{~mm}$, and mean annual wind speed is $3.7-4.2 \mathrm{~m} \mathrm{~s}^{-1}$ in the region, which comprises some patches marsh wetlands (Jia et al. 2016). The main soil types are bog soils, meadow soils and brown desert soils in the marshes.

\section{Sampling and measurement}

Sampling collection and measurement were conducted in Aug. 2016 (summer season), the mean temperature is $22 \sim 25^{\circ} \mathrm{C}$ and the precipitation is zero in the sampling period. Three marsh sites were surveyed, representing spatial repetition of the same marsh wetland type in study area, including Shuangta $\left(96^{\circ} 19^{\prime} \mathrm{E}-96^{\circ} 24^{\prime} \mathrm{E}, 40^{\circ} 31^{\prime} \mathrm{N}-\right.$ $\left.40^{\circ} 34^{\prime} \mathrm{N}\right)$, Suganhu $\left(93^{\circ} 46^{\prime} \mathrm{E}-94^{\circ} 01^{\prime} \mathrm{E}, 38^{\circ} 51^{\prime} \mathrm{N}-38^{\circ} 55^{\prime} \mathrm{N}\right)$ and Yanchiwan $\left(93^{\circ} 48^{\prime} \mathrm{E}-93^{\circ} 51^{\prime} \mathrm{E}, 40^{\circ} 21^{\prime} \mathrm{N}-40^{\circ} 22^{\prime} \mathrm{N}\right.$ ) (Fig. 1). Within each marsh site, SWC was assessed by W.E.T Sensor (Delta-T WET-2, U.K.) from the waters to the desert soil in $0-60 \mathrm{~cm}$, meantime changes in $P$. australis community horizon structure and composition were observed. three different zonation representing the distinct soil water gradient $(33.38 \pm 1.40,15.97 \pm 1.99$ and $10.22 \pm$ $1.61 \%$ ) were identified based on the distance from the waters, and then established three plots $(30 \mathrm{~m} \times 30 \mathrm{~m})$ in parallel on each zonation of similar SWC. In each plot, three random quadrats $(1 \mathrm{~m} \times 1 \mathrm{~m})$ were established to measure plant communities' characteristics and to acquire soil sampling (Fig. 1). Overall, 27 plots and 81 quadrats in three marsh sites were surveyed. $P$. australis was the single dominant species in the community of all marsh sites. The three marsh sites are all located in arid areas. The climate and soil conditions for the growth of $P$. australis are similar. The $P$. australis mainly grow within a certain distance near the edge of the water (reservoir or lake) (Fig. 1).

In each quadrat, the $P$. australis cover was estimated by the projection method. Density of $P$. australis in each quadrat was determined by the count method. The aboveground biomass was harvested for $P$. australis in each quadrat, and the constant weight of aboveground biomass was obtained by the drying oven at $70^{\circ} \mathrm{C}$ for $48 \mathrm{~h}$. The composite soil samples at a depth of $0-60 \mathrm{~cm}$ depth from three random samples were collected by a $5 \mathrm{~cm}$ diameter soil auger in each quadrat. Meanwhile, the SWC from soil samples of the same depth was measured in each quadrat. The $\mathrm{pH}$ value of soil was determined in a 1:2.5 soil water solution (Sartourius PB-10, Germany). Soil salinity (SS) was determined in a 1:5 soil water solution by conductivity meter (Mettler Toledo FE32-Meter, Switzerland). Soil organic carbon (SOC) was determined by $\mathrm{K}_{2} \mathrm{Cr}_{2} \mathrm{O}_{7}$ volumetric dilution heating method (Sprintsin et al. 2009). Soil total nitrogen (STN) was determined by micro-Kjeldahl 
method (Cao et al. 2019). Soil total phosphorus (STP) was determined by ammonium molybdate method after persulfate oxidation (Cao et al. 2019). Alkaline hydrolyzable $\mathrm{N}$ (AN) was determined by Alkaline Diffusion method (Shang et al. 2014). Available P (AP) was determined by sodium bicarbonate Olsen method (Schade et al. 2003).

\section{Trait sampling and measurement}

Nine traits of $P$. australis were measured, including leaf thickness (LT), leaf area (LA), specific leaf area (SLA), leaf dry matter content (LDMC), maximum height (MH), leaf carbon content (LCC), leaf nitrogen content (LNC), and leaf phosphorous content (LPC) (see Table 1 for ecological significance) (Pérez et al. 2013). The contents of carbon, nitrogen and phosphorus in leaves were measured for three individuals of $P$. australis in each plot, and they were determined in the laboratory. Other traits were quantified on the spot for $P$. australis by sampling 5 individuals. The measurements are showed in Table 1 (Pérez et al. 2013).

\section{Statistical analysis}

All data of plant traits and soil properties in each plot were first calculated using the arithmetic mean of three quadrats, and then all plot data in each site meet the homogeneity of variance and normality by $\log 10$ transformed. All soil properties data were of soil profile of $0-60 \mathrm{~cm}$ depth; averages of three soil depths (0-20, 20-40 and 40-60 cm). One-way analysis of variance (ANOVA) was applied to examine the difference of $P$. australis community characteristics, functional traits and soil properties in different SWC. Least significant difference (LSD) test was used to compare treatments means. Redundancy analysis (RDA) and Pearson correlations analysis were used to quantify association between $P$. australis functional traits and soil properties and trait-trait relationships across all sites, treating traits and soil properties by log-transformed. Redundancy analysis (RDA) was performed using R. v. 3.6.2 and Canoco5.0. Others analyses were carried out in IBM SPSS Statistics 19.0.

\section{Results}

\section{Phragmites australis community characteristics and soil properties in different SWC}

Coverage, density and aboveground biomass of $P$. australis community were significantly greater in the soil high water content compared with the soil low water content $(P<0.05$; Table 2). No significant difference in $\mathrm{pH}$ was measured among different SWC $(P>0.05)$. In the high water content, SWC and SS were both significantly higher $(P<0.05)$ than the other two water contents. The SOC, STN and AN had non-significant difference among the three SWCs. In the medium water content, STP and AP were relatively higher than the other two water contents, yet the significant difference between high and medium water content was found for STP, and the significant difference between high and medium-low water content was found only for AP (Table 2).

\section{$P$. australis functional traits variation in different SWC}

Leaf thickness (LT) showed a gradually increasing trend along the different SWC from high to low, while SLA, MH, LNC and LPC showed a decreasing trend (Fig. 2). It was observed that LT was significantly thinner in the high water content soil than the low water content soil $(P<0.05$, Fig.2), whereas SLA, MH and LPC were significantly greater in the high water content of soil than the low water content of soil. No significant difference in LA, LDMC, LCC and LNC was obtained among three SWC $(P>0.05$, Fig. 2).

Relationships between $\boldsymbol{P}$. australis functional traits and soil properties variables

In the RDA, the soil properties variables explained $53.7 \%$ of the total variance in the $P$. australis functional traits, and Monte Carlo test showed that all axes were significantly correlated (Table 3). The first two axis explained 32.7 and $9.9 \%$ of the explained variance in the RDA, respectively (Fig. 3). The first two axes accounted for $42.9 \%$ of the standardized soil properties variance. On the first axis, the most important variables were SS and AN (positive scores), two variation explained 23.3 and $5.7 \%$ of the total variance in the $P$. australis functional traits, respectively (Table 3). In terms of $P$. australis traits, the same axis differentiated between LPC, SLA, LCC, LNC and LA, LDMC and LT. The second axis was mainly driven by SWC (negative scores). The variation explained $7.9 \%$ of the total variance in the $P$. australis functional traits. In terms of traits, this axis differentiated between LPC, SLA and LT.

The correlation analyses exhibited LT had significantly positive correlation with $\mathrm{SS}(P<0.01)$, while it was significant negatively correlated to $\operatorname{SWC}(P<0.01)$. The SLA was significant negatively correlated to SS $(P<$ $0.01)$, STN and AN $(P<0.05)$. The LDMC had significant positively correlation with $\mathrm{SS}, \mathrm{AN}(P<0.01)$ and STN, SOC $(P<0.05)$, and LA had significant positively correlation with AN $(P<0.01)$, STN and SOC $(P<0.05)$. The LPC was significant positively correlated to SWC $(P<$ $0.05)$, while it significant negatively correlated to SS $(P<$ 0.01) (Table 4).

\section{Trait-trait relationships}

Considering all sites, SLA was significant positively related to $\operatorname{LCC}, \operatorname{LNC}$ and $\operatorname{LPC}(P<0.01)$, whereas it was 
Table 1: Determination of functional traits in P. australis

\begin{tabular}{|c|c|c|}
\hline Traits/Unit & Significance & Test methods \\
\hline $\mathrm{LT}(\mathrm{mm})$ & $\begin{array}{l}\text { Related to utilization strategies of resource for } \\
\text { species. It is usually related to leaf toughness }\end{array}$ & $\begin{array}{l}\text { Using micrometer to measure leaf thickness of a single, the measurement to avoid the } \\
\text { midrib, the blade flat place to measure }\end{array}$ \\
\hline $\mathrm{LA}\left(\mathrm{cm}^{2}\right)$ & $\begin{array}{l}\text { Indicating the ability of plants to photosynthesis } \\
\text { and water use } \mathrm{e}^{3}\end{array}$ & $\begin{array}{l}\text { The scanner scans the leaf blades and the MapInfo software calculates and takes the } \\
\text { average worth of single leaf area }\end{array}$ \\
\hline $\operatorname{SLA}\left(\mathrm{cm}^{2} \cdot \mathrm{g}^{-1}\right)$ & $\begin{array}{l}\text { Indicator of plant photosynthetic rate, relative } \\
\text { growth rate, nutrient use efficiency }{ }^{3}\end{array}$ & $\begin{array}{l}\text { Based on the measure of leaf area, } 70^{\circ} \mathrm{C} \text { drying leaves of three individual in } \\
\text { Phragmites australis to constant weight. the average SLA for each individual plant, } \\
\text { SLA = LA/ leaf dry weight of an individual }\end{array}$ \\
\hline $\operatorname{LDMC}\left(\mathrm{g} \mathrm{g}^{-1}\right)$ & $\begin{array}{l}\text { Related to ecological functions such as resource } \\
\text { utilization }^{3}\end{array}$ & LDMC = leaf dry weight/leaf saturated fresh weight \\
\hline $\mathrm{MH}(\mathrm{cm})$ & $\begin{array}{l}\text { Plant Resource Competitiveness and Reproductive } \\
\text { Strategy }\end{array}$ & $\begin{array}{l}\text { Selecting the complete plant with the highest height, and measure the vertical height } \\
\text { with a ruler }\end{array}$ \\
\hline $\operatorname{LCC}\left(\mathrm{mg} \mathrm{g}^{-1}\right)$ & $\begin{array}{l}\text { Indicator nutritional quality and palatability of } \\
\text { leaves }^{3}\end{array}$ & $\mathrm{~K}_{2} \mathrm{Cr}_{2} \mathrm{O}_{7}$ volumetric dilution heating method \\
\hline $\mathrm{LNC}\left(\mathrm{mg} \mathrm{g}^{-1}\right)$ & $\begin{array}{l}\text { Related to plant growth and photosynthetic } \\
\text { capacity. Nitrogen is the main nutrient element } \\
\text { limiting plant growth }\end{array}$ & Kjeldahl analysis method \\
\hline $\operatorname{LPC}\left(\mathrm{mg} \mathrm{g}^{-1}\right)$ & Related to plant growth and productivity ${ }^{4}$ & Molybdenum anti-colorimetric method \\
\hline
\end{tabular}

Table 2: $P$. australis community characteristics and soil properties in different $\mathrm{SWC}$ (Means $\pm \mathrm{SE}$ )

\begin{tabular}{llll}
\hline Treatments & $\mathrm{H}$ & $\mathrm{M}$ & $\mathrm{L}$ \\
\hline P. australis community characteristics & & & \\
Coverage (\%) & $85.30 \pm 3.95 \mathrm{a}$ & $70.45 \pm 6.30 \mathrm{a}$ & $51.63 \pm 5.45 \mathrm{~b}$ \\
Density(individual plant $\left.{ }^{-2}\right)$ & $88.81 \pm 15.40 \mathrm{a}$ & $78.00 \pm 14.51 \mathrm{a}$ & $48.04 \pm 7.64 \mathrm{~b}$ \\
Aboveground biomass $\left(\mathrm{g} \mathrm{m}^{-2}\right)$ & $475.89 \pm 81.65 \mathrm{a}$ & $357.82 \pm 33.07 \mathrm{a}$ & $224.83 \pm 17.61 \mathrm{~b}$ \\
Soil properties & & & $8.25 \pm 0.10 \mathrm{a}$ \\
$\mathrm{pH}$ & $8.41 \pm 0.08 \mathrm{a}$ & $8.11 \pm 0.13 \mathrm{a}$ & $10.22 \pm 1.61 \mathrm{c}$ \\
Soil water content $(\%)$ & $33.38 \pm 1.40 \mathrm{a}$ & $15.97 \pm 1.99 \mathrm{~b}$ & $23.28 \pm 4.38 \mathrm{~b}$ \\
Soil salinity $\left(\mathrm{g} \mathrm{kg}^{-1}\right)$ & $2.24 \pm 0.45 \mathrm{a}$ & $11.92 \pm 4.23 \mathrm{a}$ & $10.19 \pm 2.15 \mathrm{a}$ \\
Soil organic carbon $\left(\mathrm{g} \mathrm{kg}^{-1}\right)$ & $7.60 \pm 1.15 \mathrm{a}$ & $10.06 \pm 2.14 \mathrm{a}$ & $0.72 \pm 0.13 \mathrm{a}$ \\
Soil total nitrogen $\left(\mathrm{g} \mathrm{kg}^{-1}\right)$ & $0.57 \pm 0.07 \mathrm{a}$ & $0.63 \pm 0.15 \mathrm{a}$ & $0.35 \pm 0.02 \mathrm{ab}$ \\
Soil total phosphorus $\left(\mathrm{g} \mathrm{kg}^{-1}\right)$ & $0.25 \pm 0.05 \mathrm{a}$ & $0.42 \pm 0.06 \mathrm{~b}$ & $47.57 \pm 8.52 \mathrm{a}$ \\
Soil available nitrogen $\left(\mathrm{mg} \mathrm{kg}^{-1}\right)$ & $39.49 \pm 4.83 \mathrm{a}$ & $42.87 \pm 8.61 \mathrm{a}$ & $20.98 \pm 2.36 \mathrm{~b}$ \\
Soil available phosphorus $\left(\mathrm{mg} \mathrm{kg}^{-1}\right)$ & $12.71 \pm 2.60 \mathrm{a}$ & $24.08 \pm 4.33 \mathrm{~b}$ & \\
\hline H=
\end{tabular}

$\mathbf{H}=$ High water content ( $\mathrm{n}=9) ; \mathbf{M}=$ Medium water content ( $\mathrm{n}=9) ; \mathbf{L}=$ Low water content $(\mathrm{n}=9)$

Different lower case letters from mean values indicate the statistical difference among different SWC at $P<0.05$

significantly negatively correlated to LT and LDMC $(P<$ 0.01). LDMC had significant positively correlation with LT $(P<0.05)$ and LA $(P<0.01)$, but it had significantly negative correlation with LCC, LNC and LPC $(P<0.01)$. The LPC was positively correlated to LNC $(P<0.05)$, while it was negatively correlated to $\operatorname{LT}(P<0.01)$. In addition, LCC was significantly positively related to LNC and LPC $(P<0.05)$, and LA was significant positively related to $\mathrm{MH}$ $(P<0.05)$ (Table 5).

\section{Discussion}

Available water is a key limiting factor for plant growth and ecosystem productivity in semiarid and arid regions (Liu et al. 2009). In the present study, significant differences in coverage, density and aboveground biomass of $P$. australis community were observed between the high, medium and low water contents soils (Table 2), which concurred with Yang et al. (2011). Higher SWC had higher coverage, density and aboveground biomass, because it facilitated the root system of $P$. australis to obtain resource (e.g., water, nutrients) for better growth (Yang et al. 2011). The positive effects of SWC on $P$. australis community were also reflected the competitive advantages of the dominant species through high richness on resources (Aan et al. 2006; Yang et al. 2011). Soil $\mathrm{pH}$ is principally determined by climate, hydrology and geological settings, which may produce more alkaline soil due to their comprehensive effects in arid regions. In the present study, soil $\mathrm{pH}$ was not different across SWC gradients and different sites (Table 2). This might be due to limited leaching and slow rates of weathering and soil development in the arid regions (Ayoubi et al. 2014; Yuan et al. 2017). The SS with low water content was the highest (Table 2), as SS is characterized by surface accumulation in arid regions through strong evaporation of SWC (Wang et al. 2008), which is a driving factor for the accumulation of soluble salt in the surface layer (Peck and Hatton 2003). In the study area, the average SOC increased with the decrease of SWC due to higher SS that constrained the decomposition rate of SOC and enhanced the accumulation of SOC (Elgharably and Marschner 2011). The STN and AN were not different 
Table 3: The explained variance of soil properties variable and their significant analysis in the first two axes in redundancy analysis (RDA) ordination

\begin{tabular}{|c|c|c|c|c|c|}
\hline Soil properties variable & RDA1 & RDA2 & Explains (\%) & $F$ & $P$ \\
\hline SS & 0.7678 & -0.5077 & 23.30 & 7.60 & $0.002^{* *}$ \\
\hline AN & 0.7223 & -0.0525 & 5.70 & 2.20 & $0.048^{*}$ \\
\hline STN & 0.6459 & -0.1797 & 0.30 & 0.10 & 0.996 \\
\hline SOC & 0.6325 & -0.0596 & 3.60 & 1.50 & 0.186 \\
\hline AP & 0.3205 & -0.3136 & 5.90 & 2.20 & 0.050 \\
\hline STP & -0.1383 & -0.2962 & 4.10 & 1.50 & 0.150 \\
\hline $\mathrm{pH}$ & -0.1422 & -0.4184 & 2.90 & 1.20 & 0.330 \\
\hline SWC & -0.2220 & 0.6667 & 7.90 & 2.70 & $0.034^{*}$ \\
\hline
\end{tabular}

On All Axes: $F=2.6, P=0.002$

$*, * *=$ Significant at $P<0.05, P<0.01$

Here $\mathrm{SS}=$ soil salinity, $\mathrm{AN}=$ available nitrogen, $\mathrm{STN}=$ soil total nitrogen, $\mathrm{SOC}=$ soil organic carbon, $\mathrm{AP}=$ available phosphorus, $\mathrm{STP}=$ soil total phosphorus, $\mathrm{SWC}=$ soil water content
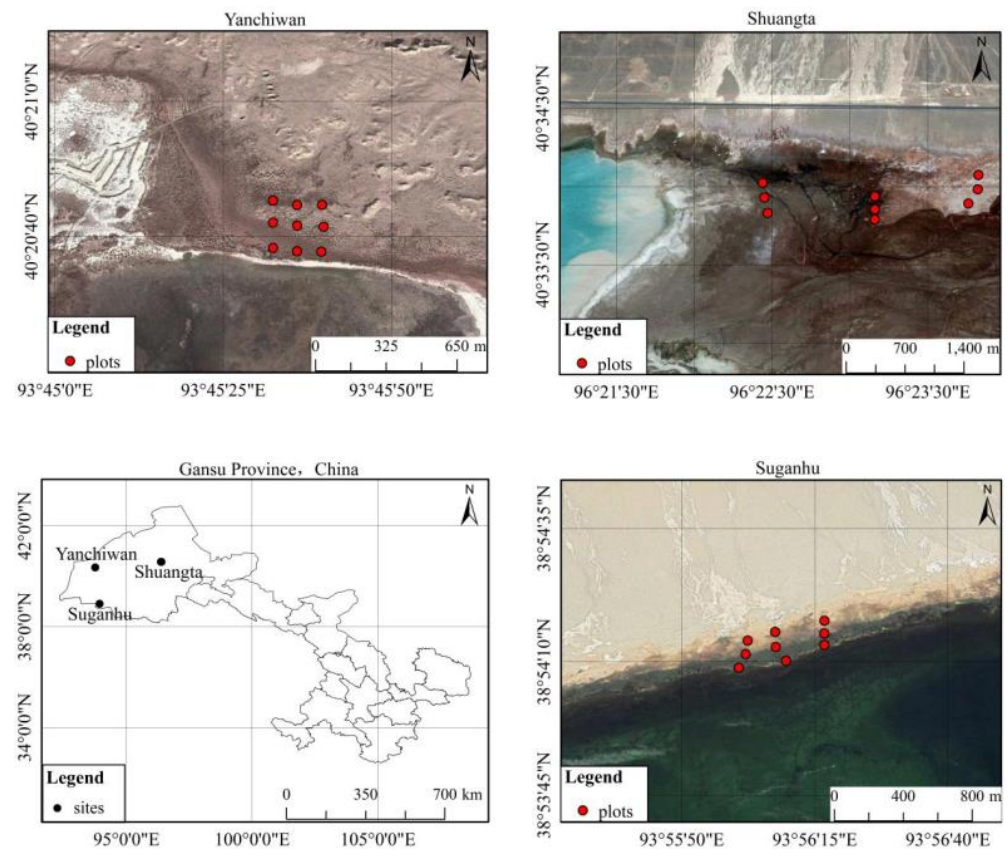

Fig. 1: Location of three marsh sites of the middle-lower reaches of the Shule River Basin

among three SWC gradients (Table 2) because STN and AN depend on decomposition of soil organic matter based on closely coupled with SOC (Wieder et al. 2015; Göransson et al. 2016). However, STP and AP were significantly higher in medium water content than that in high water content. A possible explanation is that the interdependent effect of SWC and SS promotes the dissolution and precipitation of phosphorus, which in turn facilitates the increase in the content of various forms of phosphorus in the soil (Hartzell and Jordan 2012).

Functional traits of $P$. australis were changed due to variations in nutrients under divergent SWC (Fig. 2), supporting the hypothesis of study. Functional traits are related to the acquisition of plant resources (water and nutrient), photosynthetic capacity and reproduction strategies (Westoby et al. 2002; Pérez et al. 2013; Scalon et al. 2017). In this study, lower SWC resulted more LT and LDMC, lower SLA, MH, LNC and LPC (Fig. 2). Generally, the greater LT and LDMC in plants have resistance to environmental stress (e.g., water shortage) in order to use limited resource (Maharjan et al. 2011). A relatively lower SLA of $P$. australis appeared in low water content to strengthen the photosynthetic efficiency of the leaves and reduce water loss (Shipley et al. 2005; Maharjan et al. 2011). In an earlier study, it was found that plants have higher nutrient concentrations in arid regions (Wright and Westoby 2003); which is inconsistent with the present study findings. A possible explanation is that higher LPC of $P$. australis in the high or medium SWC may be caused by altering the growth rate and improving the resorption efficiency of phosphorus by oneself (Richardson et al. 1999). In addition, in the present study, no significant difference in LA, LDMC, LCC and LNC was found among three water content gradients (Fig. 2), and thus the response of functional traits of $P$. australis to SWC is still required further research. The response of plant functional traits to 
Functional Traits of Phragmites Australis / Intl J Agric Biol, Vol 25, No 1, 2021

Table 4: Pearson's correlation coefficient between functional trait and soil properties across all sites

\begin{tabular}{|c|c|c|c|c|c|c|c|c|}
\hline & LT & LA & SLA & LDMC & LCC & LNC & LPC & MH \\
\hline$\overline{\text { SS }}$ & $\mathbf{0 . 6 7 3}^{* *}$ & 0.174 & $-0.699^{* * *}$ & $0.516^{* *}$ & -0.160 & -0.312 & $-0.611^{* * *}$ & -0.211 \\
\hline AN & 0.130 & $0.611^{* *}$ & $-0.447^{*}$ & $0.635^{* *}$ & -0.090 & -0.252 & -0.361 & 0.333 \\
\hline STN & 0.142 & $0.431^{*}$ & $-0.384^{*}$ & $0.469^{*}$ & 0.001 & -0.009 & -0.334 & 0.154 \\
\hline SOC & 0.038 & $0.469^{*}$ & -0.349 & $0.470^{*}$ & 0.022 & -0.257 & -0.199 & 0.278 \\
\hline AP & 0.289 & 0.114 & -0.265 & 0.224 & 0.292 & 0.138 & -0.264 & 0.049 \\
\hline STP & 0.235 & -0.182 & -0.112 & -0.092 & 0.267 & -0.063 & -0.161 & -0.065 \\
\hline $\mathrm{pH}$ & -0.065 & 0.016 & -0.062 & 0.066 & -0.020 & 0.158 & -0.098 & -0.278 \\
\hline SWC & $-0.744^{* *}$ & -0.050 & $0.564^{* *}$ & -0.305 & 0.115 & 0.181 & $\mathbf{0 . 5 3 8}^{* *}$ & 0.061 \\
\hline
\end{tabular}

$*$, **= Significant at $P<0.05, P<0.01$

Here $\mathrm{LT}=$ leaf thickness, $\mathrm{LA}=$ leaf area, $\mathrm{SLA}=$ specific leaf area, $\mathrm{LDMC}=$ leaf dry matter content, $\mathrm{MH}=$ maximum height, $\mathrm{LCC}=$ leaf carbon content, $\mathrm{LNC}=$ leaf nitrogen content, $\mathrm{LPC}=$ leaf phosphorous content, $\mathrm{SS}=$ soil salinity, $\mathrm{AN}=$ available nitrogen, $\mathrm{STN}=$ soil total nitrogen, $\mathrm{SOC}=$ soil organic carbon, $\mathrm{AP}=$ available phosphorus, $\mathrm{STP}=$ soil total phosphorus, $\mathrm{SWC}=$ soil water content
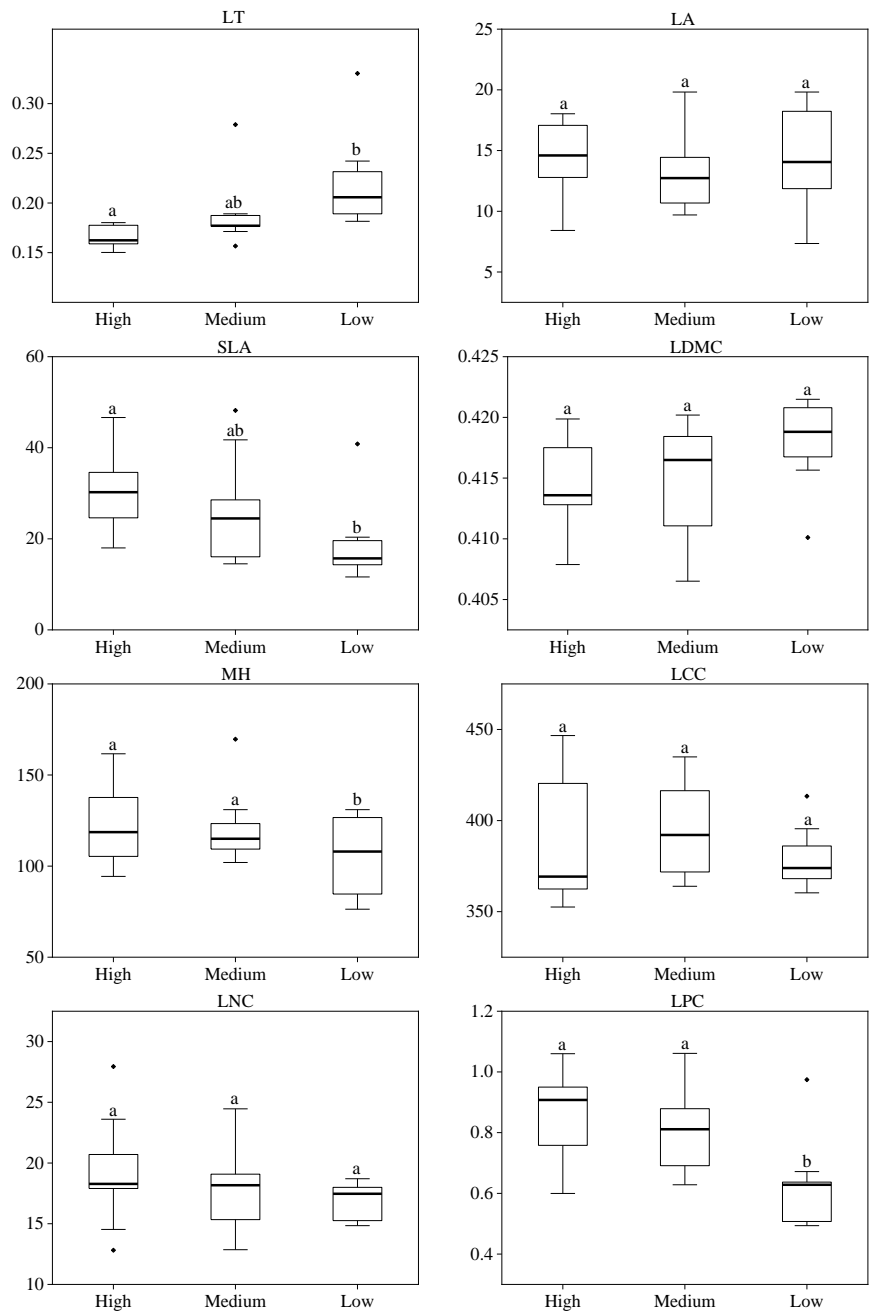

Fig. 2: Boxplots of untransformed P. australis traits for LT, LA, SLA, LDMC, MH, LCC, LNC, LPC in different SWC High: High water content $(\mathrm{n}=9)$; Medium: Medium water content ( $\mathrm{n}=9)$; Low: Low water content $(\mathrm{n}=9)$

Different lower letters indicate significant differences in different SWC at $P<0.05$

Here $\mathrm{LT}=$ leaf thickness, $\mathrm{LA}=$ leaf area, $\mathrm{SLA}=$ specific leaf area, $\mathrm{LDMC}=$ leaf dry matter content, $\mathrm{MH}=$ maximum height, $\mathrm{LCC}=$ leaf carbon content, $\mathrm{LNC}=$ leaf nitrogen content, $\mathrm{LPC}=$ leaf phosphorous content

environment changes is not only reflected in independent functional traits, but also reflected in the coordinated combination of multiple functional traits (Kühner and Kleyer 2009). Low SLA, thick LT and low LNC coordinate each other in order to high-efficiently make use of limited resources under conditions of poor resources (Bernard et al. 2012). As our hypothesis, the findings demonstrated that functional traits were a series of synergistically associations 
Zhang et al. / Intl J Agric Biol, Vol 25, No 1, 2021

Table 5: Pearson's correlation coefficient among functional traits across all sites

\begin{tabular}{|c|c|c|c|c|c|c|c|c|}
\hline & LT & LA & SLA & LDMC & LCC & LNC & LPC & MH \\
\hline$\overline{\mathrm{LT}}$ & 1 & & & & & & & \\
\hline LA & 0.145 & 1 & & & & & & \\
\hline SLA & $-0.634^{* *}$ & -0.149 & 1 & & & & & \\
\hline LDMC & $0.476^{*}$ & $0.662^{* *}$ & $-0.790^{* * *}$ & 1 & & & & \\
\hline $\mathrm{LCC}$ & -0.286 & -0.085 & $0.580^{* *}$ & $-0.443^{*}$ & 1 & & & \\
\hline LNC & -0.348 & -0.227 & $0.522^{* *}$ & $-0.539^{* *}$ & $0.690^{* *}$ & 1 & & \\
\hline LPC & $-0.652^{* *}$ & -0.267 & $0.676^{* *}$ & $-0.625^{* *}$ & $0.428^{*}$ & $0.452^{*}$ & 1 & \\
\hline MH & 0.048 & $0.435^{*}$ & -0.095 & 0.335 & -0.055 & -0.225 & -0.005 & 1 \\
\hline
\end{tabular}

Here LT= leaf thickness, LA= leaf area, SLA= specific leaf area, LDMC= leaf dry matter content, MH= maximum height, LCC= leaf carbon content, LNC= leaf nitrogen content, $\mathrm{LPC}=$ leaf phosphorous content, $\mathrm{SS}=$ soil salinity, $\mathrm{AN}=$ available nitrogen, $\mathrm{STN}=$ soil total nitrogen, $\mathrm{SOC}=$ soil organic carbon, $\mathrm{AP}=$ available phosphorus, $\mathrm{STP}=$ soil total phosphorus, $\mathrm{SWC}=$ soil water content

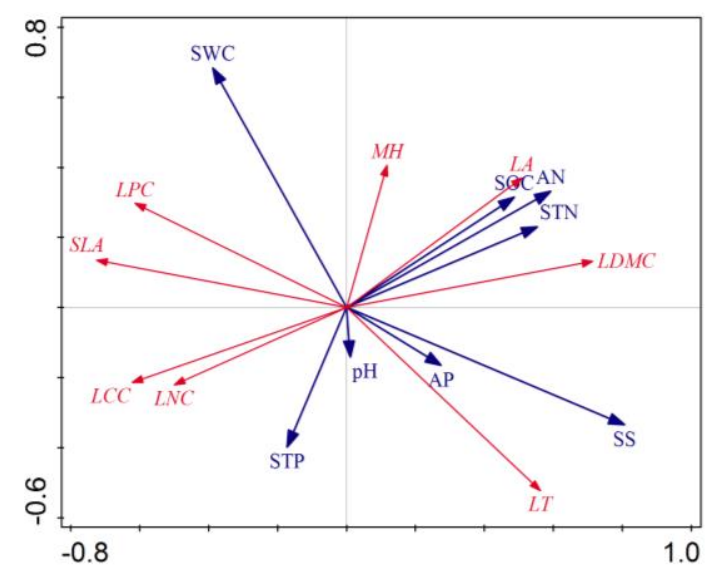

Fig. 3: RDA where the soil properties variables explained $53.7 \%$ of the total variance in the P. australis functional traits (RDA1=32.96\%; RDA2 $=9.91 \%$ )

Here $\mathrm{SWC}=$ soil water content, $\mathrm{SS}=$ soil salinity, $\mathrm{SOC}=$ soil organic carbon, $\mathrm{STN}=$ soil total nitrogen, $\mathrm{STP}=$ soil total phosphorus, $\mathrm{AN}=$ available nitrogen, $\mathrm{AP}=$ available phosphorus

(Table 4). These results agreed with the finding that previous studies have shown (Du et al. 2015), suggesting that $P$. australis had 'slower' leaves (i.e., low SLA and LNC and LPC, and high LDMC and LT) and conservative strategy (Schleip et al. 2013; Moreno et al. 2014; Jager et al. 2015). P. australis adjust the strategies for resource use and allocation through the coordinated changes of multiple functional traits to cope with resource-poor habitats in marshes of arid regions, reflecting trade-offs relationship of $P$. australis functional traits. $P$. australis exhibited a higher phenotypic plasticity in poor-resources marshes of arid areas (Van et al. 1993).

In terms of the results of RDA (Table 3), SS and AN were the dominate factors in driving the variation of $P$. australis functional traits. The influence of SS on these functional traits mainly reflects the survival strategy in $P$. australis under saline stress. A simulate experimental study proved that $\mathrm{SS}$ weakened $\mathrm{CO}_{2}$-assimilation and resulted in reducing aboveground biomass production and growth in plants (Eller et al. 2014). P. australis overcome the osmotic effects and ionic toxicity of SS stress by the above way. As SS diminished SLA, LPC, LDMC and LT increased in $P$. australis due to decrease in photosynthetic rate (Eller et al. 2014; Hameed et al. 2019). Soil AN, an effective nutrient that can be directly absorbed by plants, affects ecological processes such as plant root invasion, vegetation litter input, and absorption and release of microbial metabolite, which may cause the variation of LA and LDMC in P. australis by promoting photosynthesis and increasing dry matter accumulation (Miatto et al. 2016). The AN was positively correlated with LA and LDMC, while it was negatively correlated with SLA (Table 4). This supported the findings that soil fertility can induce a coordinated response of multiple independent functional traits (Jager et al. 2015).

\section{Conclusion}

Results indicated that divergent soil water contents affected the functional traits of $P$. australis mainly by its effect on soil salinity and available nitrogen. Moreover, due to conservative strategy, $P$. australis adapted well the resourcepoor habitats in marshes of arid regions through the coordinated combination of multiple functional traits i.e. low specific leaf area, leaf nitrogen content and leaf phosphorous content, high leaf dry matter content and leaf thickness.

\section{Acknowledgement}

This work was supported by the National Natural Science 
Foundation of China (41461012), the Natural Science Foundation of Gansu province, China (1208RJAZ114).

\section{Author Contributions}

Jian Zhang and Jianjun Cao designed the research and methodology. Huanjie Xie, Xiaohong Ma and Xiaogang Dong conducted the investigation. Huanjie Xie and Xiaogang Dong analyzed data. Jian Zhang, Huanjie Xie and Xiaogang Dong wrote the original draft. All of the authors reviewed the manuscript.

\section{References}

Aan A, L Hallik, O Kull (2006). Photon flux partitioning among species along a productivity gradient of an herbaceous plant community. $J$ Ecol 94:1143-1155

Ayoubi S, S Amiri, S Tajik (2014). Lithogenic and anthropogenic impacts on soil surface magnetic susceptibility in an arid region of Central Iran. Arch Agron Soil Sci 60:1467-1483

Barbieri M, L Ricolfi, M Battistel, A Nigro, A Garone, F Ferranti, G Sappa (2019). Monitoring wetland deterioration in a coastal protected area in central Italy: Implications for management. Eur-Mediterr $J$ Environ Integr 4; Article 37

Bernard VM, M Navas, M Vellend, C Violle, A Fayolle, E Garnier (2012). Community assembly along a soil depth gradient: Contrasting patterns of plant trait convergence and divergence in a Mediterranean rangeland. J Ecol 100:1422-1433

Cao J, Y Gong, JF Adamowski, RC Deo, G Zhu, X Dong, X Zhang, H Liu, C Xin (2019). Effects of stand age on carbon storage in dragon spruce forest ecosystems in the upper reaches of the Bailongjiang River basin, China. Sci Rep 9; Article 3005

Chen YH, WX Han, LY Tang, ZY Tang, JY Fang (2013). Leaf nitrogen and phosphorus concentrations of woody plants differ in responses to climate, soil and plant growth form. Ecography 36:178-184

Cianciaruso MV, IA Silva, MA Batalha, KJ Gaston, OL Petchey (2012). The influence of fire on phylogenetic and functional structure of woody savannas: Moving from species to individuals. Persp Plant Ecol Evol Syst 14:205-216

Du H, W Peng, T Song, F Zeng, K Wang, M Song, H Zhang (2015). Spatial pattern of woody plants and their environmental interpretation in the karst forest of southwest China. Plant Biol 149:121-130

Elgharably A, P Marschner (2011). Microbial activity and biomass and N and $\mathrm{P}$ availability in a saline sandy loam amended with inorganic $\mathrm{N}$ and lupin residues. Eur J Soil Biol 47:310-315

Eller F, H Skálová, JS Caplan, GP Bhattarai, MK Burger, JT Cronin, WY Guo, X Guo, ELG Hazelton, KM Kettenring, C Lambertini, MK McCormick, LA Meyerson, TJ Mozdzer, P Pyšek, BK Sorrell, DF Whigham, H Brix (2017). Cosmopolitan species as models for ecophysiological responses to global change: The common reed Phragmites australis. Front Plant Sci 8; Article 1833

Eller F, C Lambertini, LX Nguyen, H Brix (2014). Increased invasive potential of non-native Phragmites australis: Elevated $\mathrm{CO}_{2}$ and temperature alleviate salinity effects on photosynthesis and growth. Glob Change Biol 20:531-543

Engloner AI (2004). Annual growth dynamics and morphological differences of reed (Phragmites australis [Cav.] Trin. ex Steudel) in relation to water supply. Funct Ecol Plants 199:256-262

Gong CM, J Bai, JM Deng, GX Wang, XP Liu (2011). Leaf anatomy and photosynthetic carbon metabolic characteristics in Phragmites communis in different soil water availability. Plant Ecol 212:675687

Göransson H, M Welc, EK Bünemann, I Christl, HO Venterink (2016). Nitrogen and phosphorus availability at early stages of soil development in the Damma glacier forefield, Switzerland, implications for establishment of $\mathrm{N}_{2}$-fixing plants. Plant Soil 404:251-261
Guo X, Q Feng, W Liu, Z Li, X Wen, J Si, H Xi, R Guo, B Jia (2015). Stable isotopic and geochemical identification of groundwater evolution and recharge sources in the arid Shule River Basin of Northwestern China. Hydrol Proc 29:4703-4718

Hameed M, M Ashraf, N Naz (2019). Anatomical adaptations to salinity in cogon grass [Imperata cylindrica (L.) Raeuschel] from the Salt Range, Pakistan. Plant Soil 322:229-238

Hartzell JL, TE Jordan (2012). Shifts in the relative availability of phosphorus and nitrogen along estuarine salinity gradients. Biogeochemistry 107:489-500

Jager MM, SJ Richardson, PJ Bellingham, MJ Clearwater, DC Laughlin (2015). Soil fertility induces coordinated responses of multiple independent functional traits. $J$ Ecol 103:374-385

Jia ZZ, J Gong, Y Zhang (2016). Nearly 35 years of oasis-desertification in the middle and lower reaches of the Shule River. Arid Zone Res 33:1294-1302

Jiang Y, R Zang, X Lu, Y Huang, Y Ding, W Liu, W Long, J Zhang, Z Zhang (2015). Effects of soil and microclimatic conditions on the community level plant functional traits across different tropical forest types. Plant Soil 1:351-367

Kołodziejek J, S Michlewska (2015). Effect of soil moisture on morphoanatomical leaf traits of Ranunculus acris (ranunculaceae). Pol $J$ Ecol 63:400-413

Kühner A, M Kleyer (2009). A parsimonious combination of functional traits predicting plant response to disturbance and soil fertility. $J$ Veg Sci 19:681-692

Liu WX, Z Zhang, QS Wan (2009). Predominant role of water in regulating soil and microbial respiration and their responses to climate change in a semiarid grassland. Glob Change Biol 15:184-195

Liu Y, Z Ding, C Bachofen, Y Lou, M Jiang, X Tang, X Lu, N Buchmann (2018). The effect of saline-alkaline and water stresses on water use efficiency and standing biomass of Phragmites australis and Bolboschoenus planiculmis. Sci Total Environ 644:207-216

Long W, R Zang, BS Schamp, Y Ding (2011). Within- and among-species variation in specific leaf area drive community assembly in a tropical cloud forest. Oecologia 4:1103-1113

Ma JZ, JH He, S Qi, GF Zhu, W Zhao, WM Edmunds, YP Zhao (2013). Groundwater recharge and evolution in the Dunhuang Basin, northwestern China. Appl Geochem 28:19-31

Maharjan SK, L Poortrer, M Holmgren, F Bongers, JJ Wieringa, WD Hawthorne (2011). Plant functional traits and the distribution of West African rain forest trees along the rainfall gradient. Biotropica 43:552-561

Maracahipes L, MB Carlucci, E Lenza, BS Marimon, BH Marimon, FA Guimaraes, MV Cianciaruso (2018). How to live in contrasting habitats? Acquisitive and conservative strategies emerge at inter- and intraspecific levels in savanna and forest woody plants. Perspect Plant Ecol Evol Syst 34:17-25

Miatto RC, IJ Wright, MA Batalha (2016). Relationships between soil nutrient status and nutrient-related leaf traits in Brazilian cerrado and seasonal forest communities. Plant Soil 404:13-33

Moreno GCA, J Schellberg, F Ewert, K Brüser, PC Prati, A Linstädte, RJ Oomen, JC Ruppert, SB Perelman (2014). Response of community-aggregated plant functional traits along grazing gradients: Insights from African semi-arid grasslands. Appl Veg Sci 17:470-481

Niu S, AT Classen, Y Luo (2018). Functional traits along a transect. Funct Ecol 32:4-9

Peck AJ, T Hatton (2003). Salinity and the discharge of salts from catchments in Australia, J Hydrol 272:191-202

Pérez HN, S Díaz, E Garnier, S Lavorel, H Poorter, P Jaureguiberry, MSB Harte, WK Cornwell, JM Craine, DE Gurvich, C Urcelay, EJ Veneklaas, PB Reich, L Poorter, IJ Wright, P Ray, L Enrico, JG Pausas, ACD Vos, N Buchmann, G Funes, F Quétier, JG Hodgson, K Thompson, HD Morgan, HT Steege, MGA van der Heijden, L Sack, B Blonder, P Poschlod, MV Vaieretti, G Conti, AC Staver, S Aquino, JHC Cornelissen (2013). New handbook for standardised measurement of plant functional traits worldwide. Aus $J$ Bot 61:167-234 
Richardson CJ, GM Ferrell, P Vaithiyanathan (1999). Nutrient effects on stand structure, resorption efficiency, and secondary compounds in Everglades sawgrass. Ecology 80:2182-2192

Scalon MC, M Haridasan, AC Franco (2017). Influence of long-term nutrient manipulation on specific leaf area and leaf nutrient concentrations in savanna woody species of contrasting leaf phenologies. Plant Soil 421:233-244

Schade JD, M Kyle, SE Hobbie, WF Fagan, JJ Elser (2003). Stoichiometric tracking of soil nutrients by a desert insect herbivore. Ecol Lett 6:96-101

Schleip I, FA Lattanzi, H Schnyder (2013). Common leaf life span of codominant species in a continuously grazed temperate pasture. Basic Appl Ecol 14:54-63

Shang ZH, JJ Cao, RY Guo, RJ Long, B Deng (2014). The response of soil organic carbon and nitrogen 10 years after returning cultivated alpine steppe to grassland by abandonment or reseeding. Catena 119:28-35

Shipley B, D Vile, E Garnier, I Wright, H Poorter (2005). Functional linkages between leaf traits and net photosynthetic rate: Reconciling empirical and mechanistic models. Funct Ecol 19:602-615

Sprintsin M, A Karnieli, S Sprintsin, S Cohen, P Berliner (2009). Relationships between stand density and canopy structure in a dryland forest as estimated by ground-based measurements and multi-spectral spaceborne images. J Arid Environ 73:955-962

Su C, Y Wang, S Ge, Z Li, J Li (2020). Origin of the Crescent Moon Spring in the Gobi Desert of northwestern China, based on understanding groundwater recharge. J Hydrol 580:124344

Van DV, RGA Boot, H Poorter, H Lambers (1993). Phenotypic plasticity in response to nitrate supply of an inherently fast-growing species from a fertile habitat and an inherently slow-growing species from an infertile habitat. Oecologia 96:548-554

Vile D, E Garnier, B Shipley, G Laurent, ML Navas, C Roumet, S Lavorel, S Díaz, JG Hodgson, F Lloret, GF Midgley, H Poorter, MC Rutherford, PJ Wilson, IJ Wright (2005). Specific leaf area and dry matter content estimate thickness in laminar leaves. Ann Bot 96:1129-1136
Wang L, G Li, Y Dong, D Han, J Zhang (2014). Using hydrochemical and isotopic data to determine sources of recharge and groundwater evolution in an arid region: A case study in the upper-middle reaches of the Shule River basin, northwestern China. Environ. Earth Sci 73:1901-1915

Wang YG, Y Li, DN Xiao (2008). Catchment scale spatial variability of soil salt content in agricultural oasis, Northwest China. Enviro Geol $56: 439-446$

Westoby M, DS Falster, AT Moles, PA Vesk, IJ Wright (2002). Plant ecological strategies: Some leading dimensions of variation between species. Ann Rev Ecol Syst 33:125-159

Wieder WR, CC Cleveland, WK Smith, BK Todd (2015). Future productivity and carbon storage limited by terrestrial nutrient availability. Nat Geosci 8:441-444

Wright IJ, M Westoby (2003). Nutrient concentration, resorption and lifespan: Leaf traits of Australian sclerophyll species. Funct Ecol 17:10-19

Wright IJ, N Dong, V Maire, IC Prentice, M Westoby, S Díaz (2017). A. Global climatic drivers of leaf size. Science 357:917-921

Xu H, Y Li (2006). Water-use strategy of three central Asian desert shrubs and their responses to rain pulse events. Plant Soil 285:5-17

Yang HJ, Y Li, M Wu, Z Zhang, L Li, S Wan (2011). Plant community responses to nitrogen addition and increased precipitation: The importance of water availability and species traits. Glob Change Biol 17:2936-2944

Yuan Y, Z Zhao, P Zhang, L Chen, T Hu, S Niu, Z Bai (2017). Soil organic carbon and nitrogen pools in reclaimed mine soils under forest and cropland ecosystems in the Loess Plateau, China. Ecol Eng 102:137144

Zuo X, J Zhang, P Lv, S Wang, Y Yang, X Yue, X Zhou, Y Li, M Chen, J Lian, H Qu, L Liu, X Ma (2018). Effects of plant functional diversity induced by grazing and soil properties on above- and belowground biomass in a semiarid grassland. Ecol Indicat 93:555-561 